\title{
A Monitoring Technique for Reversed Power Flow Detection With High PV Penetration Level
}

\author{
Hashem Mortazavi, Hasan Mehrjerdi, Member, IEEE, Maarouf Saad, Senior Member, IEEE, \\ Serge Lefebvre, Dalal Asber, and Laurent Lenoir, Member, IEEE
}

\begin{abstract}
The integration of renewable energy resources (RESs) in power systems poses many research challenges. Research shows that the RES output may exceed the consumed power during the day. Consequently, the direction of the power flow on distribution lines can be reversed during some periods. As the voltage regulator is normally designed for unidirectional power flow, this may cause voltage violations on the distribution feeder. Therefore, most utilities try to set a penetration level (PL) limit for safe operation. On the other hand, time varying and unbalanced loading are the main characteristics of distribution systems. Moreover installation of intermittent and nondispatchable photovoltaic (PV) devices increases the control problems of distribution system. This paper presents an impedance-based monitoring method for detection of distribution system current behavior. It will be shown that by utilizing this monitoring technique, not only the small variation of PV PL can be easily detected, but also some fast transients such as the effect of cloud movement on PV system can be monitored. This monitoring technique employs only local measurements of bus voltages and line current to measure the apparent impedance seen at the installation point. The practical application of measured impedance as a monitoring technique shows its effectiveness for distribution system monitoring in presence of various PV PL.
\end{abstract}

Index Terms-Monitoring, photovoltaic (PV) penetration, reverse power flow, smart grid, voltage control.

\section{INTRODUCTION}

D EREGULATION of power system, smart grid, electric vehicle, and renewable energy integration pose a lot of challenges to power systems operation. Although a lot of monitoring and protection devices are installed in transmission system due to its complexity, traditional distribution systems suffer lack of monitoring systems due to its high number of feeders and load points.

Distribution systems have been designed for radial and unidirectional power flows. In this design the active and reactive power are transferred from the transmission system

Manuscript received May 21, 2014; revised October 7, 2014 and December 8, 2014; accepted January 23, 2015. This work was supported by the Research Institute of Hydro-Quebec, Power Systems, and Mathematics, Varennes, QC, Canada. Paper no. TSG-00488-2014.

H. Mortazavi and M. Saad are with the Department of Electrical and Computer Engineering, Quebec University (ETS), Montréal, QC H3c1 K3, Canada (e-mail: hmortazavi1@gmail.com).

H. Mehrjerdi is with the Department of Electrical and Computer Engineering, Qatar University, Doha 2713, Qatar.

S. Lefebvre, D. Asber, and L. Lenoir are with the Research Institute of Hydro-Quebec, Power Systems, and Mathematics, Varennes, QC J3X 1S1, Canada.

Color versions of one or more of the figures in this paper are available online at http://ieeexplore.ieee.org.

Digital Object Identifier 10.1109/TSG.2015.2397887 to consumer. Therefore, many protection and regulation strategies in distribution network are based on this radial nature. For example, voltage regulators are designed with the flow of power from the higher voltage to the lower voltage. Integration of the renewable energy resource (RES) in distribution systems, however, show that, based on the size and the installation location, the power flow may reverse [1]. For high penetration of RES, traditional unidirectional distribution system will change to a bidirectional system which needs a revision of regulation.

According to [2], the reverse power flow is the main cause of voltage rise in distribution feeders. Customer load control is one solution for decreasing reverse power. Asari and Kobayashi [3] proposed that controlling heat pump water heaters at customer side will minimize reverse power flow and voltage violation resulting from high penetration of photovoltaic (PV). Baran et al. [4] analyze high PV penetration impacts on distribution system protection and operation. Using flexible ac transmission system and custom power devices (static VAR compensator (SVC) [5], static synchronous compensator (STATCOM) [6], distribution STATCOM (DSTATCOM) [7], superconducting magnetic energy storage (SMES) [8]), utilizing electric vehicle [9], storage system [10]-[12], and active power curtailment technique recommended in [13]-[15] are the most attractive techniques to mitigate those expected voltage violations.

Monitoring distribution system through smart meters and monitors is one of the basis of smart grid [16]. Different monitoring system approaches and devices have been proposed to assess different system conditions. Power quality monitoring systems have been used for a long time not only for analyzing power quality problems but also for load modeling [17]. Qiang et al. [18] proposed voltage monitoring of microgrid at number of buses to analyze the power quality and reliability indexes.

Using local data measurement for protection, control, and monitoring purpose is an attractive alternate solution to the electric utilities, due to lower installation costs and simplicity of operation. On-line impedance measurement based on local data has been proposed for different applications. The most important application of impedance measurement is in distance relay protection [19]. Vu et al. [20] proposed using local measured apparent impedance for voltage stability margin estimation. Cespedes and Jian [21] proposed using online grid impedance measurement for adaptive control of grid connected inverters. 
Integration of intermittent RES, like solar and wind into a radial and unidirectional power flow distribution system, implies incorporating new monitoring devices that are sensitive to rapid changes of RES generation and power flow direction. In this research, an impedance measuring technique is proposed as a monitoring tool in distribution systems. The performance of impedance seen at number of buses as a monitoring technique is analyzed in presence of RES devices. Due to unbalance loading of distribution system, it will be shown that any proposed monitoring technique shall have the capability for separate three-phases monitoring. The speed and stability of proposed monitoring technique is tested by simulation of important generation fluctuation of connected PV system due to clouds movement.

This paper is organized as follows. In Section II, the basic theory of impedance method for monitoring of distribution feeder with RES will be established. Section III describes the IEEE 13 node test feeder used as a case study for simulation. Section IV presents the simulation results of testing the proposed method for unit and nonunit power factor (pf) operation of PV inverter, fault conditions, load pf variation, and cloud movement. The practical capability of method is validated by analyzing the impact of cloud transients on IEEE 34 node test system. Finally, the conclusion is presented in Section V.

\section{Measured Impedance Theory AND its APPLICATION ON REVERSE POWER FLOW DETECTION}

\section{A. Theory of Impedance Method}

Distance relay, typically, is the first choice for transmission line protection. In recent years, it was also proposed as a protection device in distribution system [19], [22]. Distance relays use voltage and current as inputs and calculate the apparent impedance seen at the relay location. This value is a complex number which shows the apparent impedance seen by $\mathrm{V} / \mathrm{I}$ calculation. A quadrilateral characteristic-distance relay is proposed in [22] to distinguish the distribution feeder faults in presence of forward and reverse power flow due to distributed generation (DG) integration. Uthitsunthorn and Kulworawanichpong [23] proposed using distance relays for distribution feeder protection with renewable power plant to reduce protection coordination complexity due to impedance based setting of distance protection. Although this relay is geared at fast and accurate detection of faults in power system, it was shown that this method has a very good capability to measure and analyze the load conditions [24].

When the amount of active and reactive power injected or absorbed varies at distribution system nodes, the node voltage and line current will change. To clarify the effect of load variation and RES integration on apparent impedance seen at any distribution system node, let consider the simple system shown in Fig. 1.

Consider that $P_{L i}$ and $Q_{L i}$ are the total active and reactive power (line power and losses) flowing down from node $i, P_{i}$ and $Q_{i}$ are the active and reactive power of load connected to node $i$, and $R_{s i}+j X_{s i}$ is the complex line impedance.

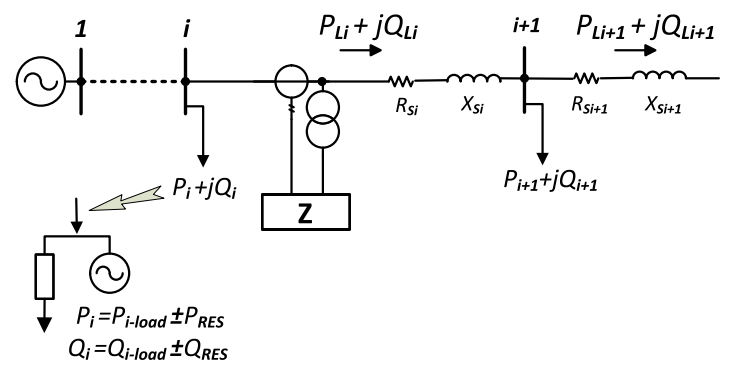

Fig. 1. Simple system schematic, the impedance measuring unit connected to sending end of line connected to bus $i$.

Voltage drop $\left(\Delta V_{i}\right)$ along the feeder between nodes $i$ and $i+1$; $\forall i=1, \ldots, n$, is defined as

$$
\begin{aligned}
\Delta V_{i} & =V_{i}-V_{i+1}=Z_{s i} \times I_{i} \\
I_{i} & =\frac{P_{L i}-j Q_{L i}}{V_{i}^{*}} \\
\Delta V_{i} & =\left(R_{s i}+j X_{S i}\right) \times \frac{P_{L i}-j Q_{L i}}{V_{i}^{*}} \\
\Delta V_{i} & =\left[\frac{R_{s i} \times P_{L i}+X_{s i} \times Q_{L i}}{V_{i}^{*}}\right]+j\left[\frac{X_{S i} \times P_{L i}-R_{s i} \times Q_{L i}}{V_{i}^{*}}\right] .
\end{aligned}
$$

As shown in (4), the voltage drop along the feeder has real and imaginary parts. If the voltage of bus $i+1$ is considered as reference point, that $V_{i+1}=\left|V_{i+1}\right| \angle 0$ (this voltage is along the positive real axis), then from (1) and (4) the voltage at node $i$ is obtained by

$$
\begin{aligned}
V_{i}=V_{i+1}+\left[\frac{R_{S i} \times P_{L i}+X_{S i} \times Q_{L i}}{V_{i}^{*}}\right] \\
+j \times\left[\frac{X_{S i} \times P_{L i}-R_{S i} \times Q_{L i}}{V_{i}^{*}}\right] .
\end{aligned}
$$

If the $V_{R}$ and $V_{X}$ are defined as (6) and (7), the voltage at node $i$ can be rewritten as

$$
\begin{aligned}
V_{R} & =V_{i+1}+\left[\frac{R_{s i} \times P_{L i}+X_{s i} \times Q_{L i}}{V_{i}^{*}}\right] \\
V_{X} & =\left[\frac{X_{s i} \times P_{L i}-R_{s i} \times Q_{L i}}{V_{i}^{*}}\right] \\
V_{i} & =V_{R}+j V_{X} .
\end{aligned}
$$

To calculate apparent impedance seen from node $i$

$$
\begin{aligned}
Z_{i} & =\frac{V_{i}}{I_{i}}=\frac{V_{R}+j V_{X}}{\frac{P_{L i}-j Q_{L i}}{V_{i}^{*}}} \\
Z_{i} & =V_{i}^{*} \times \frac{V_{R}+j V_{X}}{P_{L i}^{2}+Q_{L i}^{2}} \times\left(P_{L i}+j Q_{L i}\right) \\
A & =\frac{V_{i}^{*}}{P_{L i}^{2}+Q_{L i}^{2}} \\
Z_{i} & =A\left(V_{R}+j V_{X}\right) \times\left(P_{L i}+j Q_{L i}\right) \\
Z_{i} & =A\left[\left(V_{R} P_{L i}-V_{X} Q_{L i}\right)+j\left(P_{L i} V_{X}+V_{R} Q_{L i}\right)\right] .
\end{aligned}
$$

For node $i$, let $P_{i-\text { load }}$ and $Q_{i-\text { load }}$ be the active and reactive power of load, $P_{L i-\text { loss }}$ and $Q_{L i-\text { loss }}$ be the active and reactive losses of the line, and $P_{i-\text { RES }}, Q_{D i-\text { RES }}$ denote the active and reactive generation of RES at node $i$, respectively. 
If there is no RES connected to that node it is assumed that $P_{\mathrm{RES}}=0, Q_{\mathrm{RES}}=0$. Therefore, we can define the transmitted power through each line of the distribution network as follows:

$$
\begin{aligned}
P_{L i} & =P_{L i-\mathrm{loss}}+P_{(i+1)}+\sum_{i+1}^{n} P_{L(i+1)} \\
Q_{L i} & =Q_{L i-\mathrm{loss}}+Q_{(i+1)}+\sum_{i+1}^{n} Q_{L(i+1)} \\
P_{i} & =P_{i-\text { load }} \pm P_{i-\mathrm{RES}} \\
Q_{i} & =Q_{i-\text { load }} \pm Q_{i-\mathrm{RES} .}
\end{aligned}
$$

Then by substituting (14)-(17) in (13), it can also be expressed as

$$
Z_{i}=F\left(R_{s i}, X_{s i}, P_{L i}, Q_{L i}, P_{i-\mathrm{RES}}, Q_{i-\mathrm{RES}}\right) .
$$

From (18), it can be seen that the apparent impedance seen from node $i$ is a function of line impedance, transmitted active and reactive power of line and the injected or absorbed power at the node $i$ and rest of the network. Therefore, the impedance seen at bus $i$ can be used as a monitoring tool for analyzing the actual system situation.

\section{B. Apparent Impedance Relationship With Power Flow Direction}

As it was stated earlier, voltage and current are two inputs of the method. The calculated positive sequence of voltage and currents are used for positive sequence impedance calculation. In this section, the relationship between the calculated impedance, magnitude and direction of active and reactive power flow through the line will be established.

Consider two consecutive buses $i$ and $i+1$ in Fig. 1, $Z_{i}$ is the apparent impedance seen on the $i$ side of the line between those two consecutive buses; $P_{L i}$ and $Q_{L i}$ are the active and reactive powers of the line flowing from side $i$ to $i+1$, respectively; $\left|V_{i}\right|$ is the amplitude of the voltage at bus $i$.

Therefore the relationships between the measured $R$ and $X$ and the power transmitted through the lines are given below

$$
\begin{aligned}
I_{i} & =\left(\frac{S_{i}}{V_{i}}\right)^{*}=\left(\frac{P_{\mathrm{Li}}+j Q_{\mathrm{Li}}}{V_{i}}\right)^{*} \\
Z_{i} & =\frac{V_{i}}{I_{i}}=\frac{V_{R}+j V_{X}}{\left(\frac{P_{\mathrm{Li}}+j Q_{\mathrm{Li}}}{V_{i}}\right)^{*}} \\
Z_{i} & =\left(\frac{P_{\mathrm{Li}}+j Q_{\mathrm{Li}}}{P_{L i}^{2}+Q_{L i}^{2}}\right) \times\left|V_{i}\right|^{2} .
\end{aligned}
$$

The real and the imaginary parts of the measured impedance shown in (21) are written as

$$
\begin{aligned}
R_{i} & =\left(\frac{P_{\mathrm{Li}}}{P_{L i}^{2}+Q_{L i}^{2}}\right) \times\left|V_{i}\right|^{2} \\
X_{i} & =\left(\frac{Q_{\mathrm{Li}}}{P_{L i}^{2}+Q_{L i}^{2}}\right) \times\left|V_{i}\right|^{2} .
\end{aligned}
$$

As it can be seen from (22) and (23), the position of measured apparent impedance in $R-X$ plane depends on the

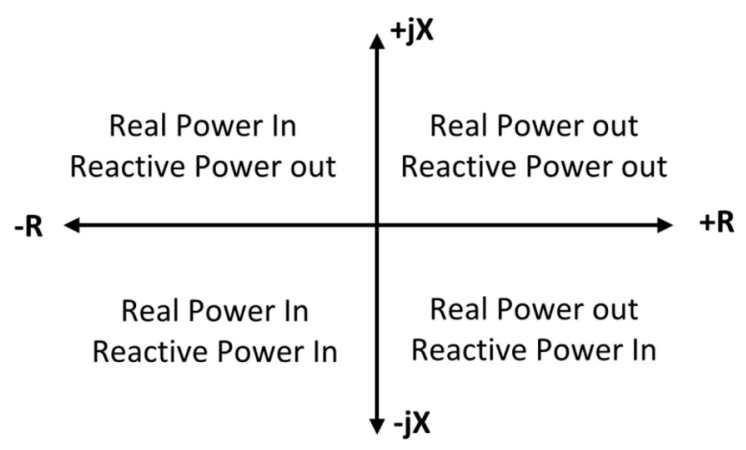

Fig. 2. Mapping of power flow direction on $R-X$ diagram [25].

value and direction of active and reactive power. The apparent impedance measured at bus $i$ has reverse relationship with power. The larger the power transferred through the line, the smaller measured $R$ and $X$.

The sign of $R_{i}$ in (22) and $X_{i}$ in (23) are only related to the sign (direction) of $P_{L i}$ and $Q_{L i}$, respectively. Then, according to (14) and (15)

$$
\begin{aligned}
& \text { If }\left|P_{i-\text { RES }}\right|>\left|P_{L(i+1)}+P_{i-\text { load }}\right| \stackrel{\text { yields }}{\longrightarrow} P_{L i}<0 \\
& \text { If }\left|Q_{i-\text { RES }}\right| \geq\left|Q_{L(i+1)}+Q_{i-\text { load }}\right| \stackrel{\text { yields }}{\longrightarrow} Q_{L i}<0 .
\end{aligned}
$$

Equations (24) and (25) show the conditions that the RES generation exceeds the consumption and the final location of the impedance seen at bus $i$ on $R-X$ plane will be at third quarter. For forward $Q$ and reversed $\mathrm{P}$ the impedance location will be at the second part of $R-X$ plain.

Based on the direction of active and reactive power flow the $R-X$ diagram can be divided into four parts, Fig. 2 shows the mapping of power flow direction on $R-X$ diagram. Based on this figure, the impedance located on $R$ axis represented a unity pf and for $x$-axis the pf is zero. For the directions of active and reactive power are from node $i$ to $i+1$, the measured impedance will be located at the first quarter of $R-X$ plane.

\section{Impedance Measurement}

Distance relay is the best tools for impedance measurement in power system. Because the positive sequence component is the only common sequence component in all the types of faults, the measured impedance at distance protection relays are always based on the phase positive sequence impedance. Moreover, the apparent impedance measured by a distance relay will depend on the current and voltage transformers connections too.

The measured impedance is calculated by three, one phase measuring units. The simplest ground distance functions use only a single phase current and a single phase voltage. Consider that $V_{A N}$ is the phase $A$ to ground voltage and $I_{A}$ is the current flows through the phase $A$ conductor, the apparent impedance seen for phase $A$ is given by [26]

$$
Z_{A}=\frac{V_{A}}{I_{A}} .
$$

The impedance calculated using (26) is the positive sequence impedance seen of the line for all system operation condition except fault conditions. Phase-ground distance 


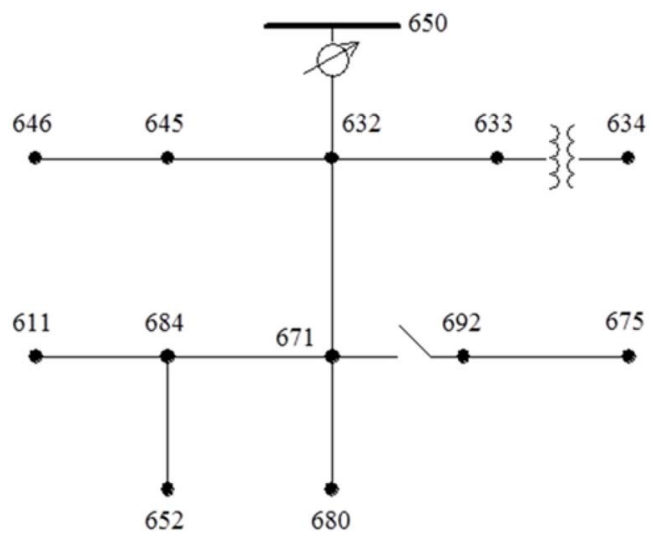

Fig. 3. Schematic of the IEEE 13 node test feeder.

relay usually employ a zero sequence current compensator for actual system impedance measurement during the fault conditions. Based on [27], all the phase-ground faults detection units measure the same impedance value for the nonfault conditions.

\section{CASE STUdy}

The IEEE 13 node test feeder (Fig. 3) is a very small but relatively highly loaded $4.16 \mathrm{kV}$ feeders. This provides a good test for the most common features of distribution analysis software [28]. As this model has unbalanced spot and distributed load, overhead lines and cables, shunt capacitors, and a voltage regulator consisting of three single-phase units, it is a good case for testing the impedance method capabilities. The simulations have been performed by OpenDSS [29] software and MATLAB [30]. The OpenDSS COM server interfaced with the MATLAB program is used for simulation.

Wind, photovoltaic (PV), and biomass are the best choices for RES integration to power system. For large scale power production at transmission level, biomass system, and wind turbine are the most obvious solution. On the other hand, small scale PV system is more attractive solution for residential installation. For RES integration to distribution system simulation, PV system is chosen.

This research used the built-in PV system model provided in OpenDSS. Among two options for modeling high penetration of small-scale rooftop PV or large centralized PV, the second one was chosen for the simulation of impedance based monitoring system. Hence to produce various scenarios for simulations, the lumped three-phases balanced PV model was added at three different locations, one close to substation source bus 632, one near the feeder midpoint bus 671, and one at the end of feeder at bus 680. For showing the effect of PV location on the proposed monitoring technique at each simulation only one location was used for PV installation.

For simulation of different penetration level (PL), Hoke et al. [31] showed that the 15\% limit for PL as a rule of thumb for most of feeders is very conservative. They showed that in two-thirds of simulated cases, the maximum PL is greater than $90 \%$. In this research, to analyze the full capability of the monitoring technique, the PV output was increased from

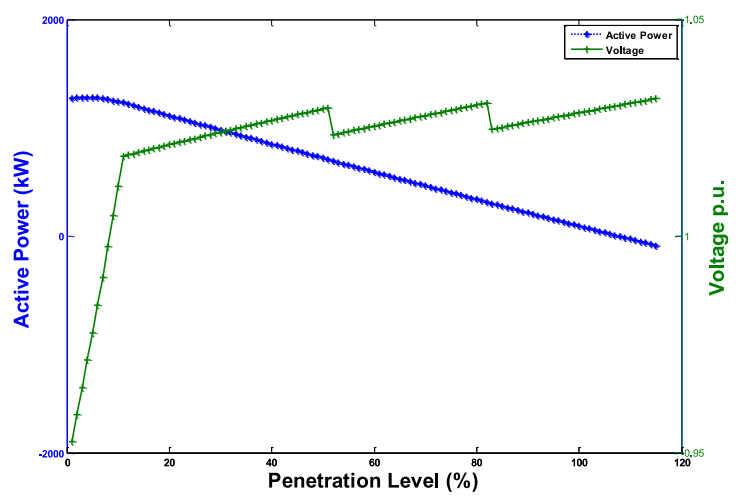

Fig. 4. Active power flows through feeder 650-632 and bus 632 voltage profile with active tap changer and PV is connected to bus 680 .

zero to 1.15 p.u. of model total load $(\mathrm{P}=3800 \mathrm{~kW})$ with step size of 0.01 (115 different PLs). At each step, a power flow was done by OpenDSS and all voltages, currents, and active and reactive power of feeder were saved. In this paper, except the under voltage and over voltage limits, other limiting factors such as feeders current rating, the substation transformer capacity, power quality issues were neglected. The simulation has been performed for both unit and nonunit pf PV operation. As the original model of IEEE 13 node test feeder does not have a load at bus 680 a $360 \mathrm{~kW}$ and $270 \mathrm{kvar}$ load connected to this bus for simulation. A three-phases 60 kvar capacitor installed at bus 680 for voltage regulation.

\section{Simulation Result and Discussion}

\section{A. Impact of PV PL on Measured Impedance}

To show the impact of PV PL the lumped model of PV is connected to bus 680 . Fig. 4 shows the active power flows through feeder $650-632$ and bus 632 voltage profile. As it can be seen, by increasing PL the active power flow from the source to grid decreases and the voltage increases. It is obvious that by increasing the PL the voltage increases, so the tap changer located between buses 650 and 632 operates two times to keep the voltage within the standard boundaries.

Fig. 5 shows the measured $R$ and $X$ for different PLs at bus 632. As it can be seen by increasing PL, the $R$ and $X$ increase till $\mathrm{PL}=0.58$ but after this point although $X$ increases the $R$ decreases. At PL $=88 \%$ the $R$ becomes zero and after this point the $R$ goes negative corresponding the reversed active power. The reason for the decreasing $R$ is related to the relationship between the measured $R$ and total $\mathrm{P}$ and $\mathrm{Q}$ flows along the line. Based on (22) by decreasing the P-due to the increased PV PL-the measured $R$ will decrease too.

As it can be seen from Figs. 4 and 5, at the time of tap changing the measured impedance shows a little change. This illustrates that the proposed method is sensitive to small variations of voltage in the system.

Unlike at bus 632, the measured impedance at bus 680 has a different trend. As it can be seen from Fig. 6 the measured $R$ and $X$ increases by increasing PV PL, but, when the active power direction is reversed, the value of $R$ decreases and becomes negative. This shows that, we have reverse active 


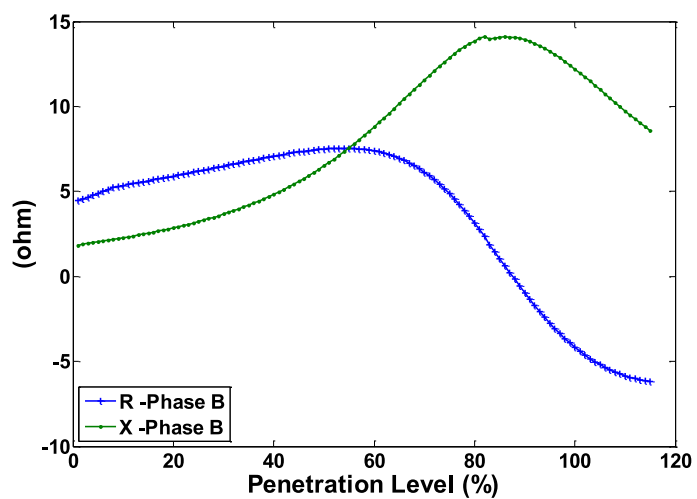

Fig. 5. Measured $R$ and $X$ versus PL at bus 632-phase $B$ with active tap changer.

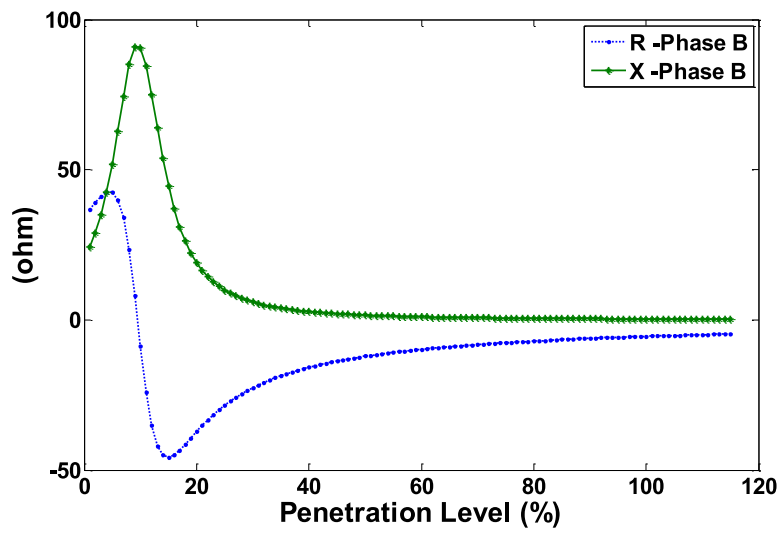

Fig. 6. Measured $R$ and $X$ versus PL at bus 680 .

power while the reactive power direction does not change (because the PV only operates at unity pf). These graphs support the basic theory of proposed method described in Section II-B.

Fig. 7 shows the measured impedance plotted on $R-X$ plane three buses for PV connected at bus 680 and PL variation between 0 and $115 \%$ of nominal load.

Fig. 7 shows the measured impedance loci of different measurement units. Fig. 7(a) shows that by increasing PL of PV system the reversed active power occurs at PL $=108 \%$ at bus 632. Meanwhile at bus 671 [Fig. 7(b)] this occurs at $\mathrm{PL}=93 \%$. In addition for bus 680 [Fig. 7(c)] the reversed active power starts at $\mathrm{PL}=9 \%$.

Fig. 7 shows that, depending on measurement unit location and PV equipment location, the value and trend of measured impedance has a unique and detectable characteristic. Based on (20), for any type of energized feeder with the voltage and current data available, the proposed monitoring technique can be used. As stated earlier, the apparent impedance measured at any bus has a direct relationship with PL and reverse with transferred power. The larger the power transferred through the line (equal to low PL), the smaller measured $R$ and $X$, and vice versa. For example at bus 632 , for PL varying from $20 \%$ (equal to high load) to $80 \%$ (equal to light load), the impedance locations varies from point $(5.904,2.955)$ to $(3.16,13.85)$ on $R-X$ plane.

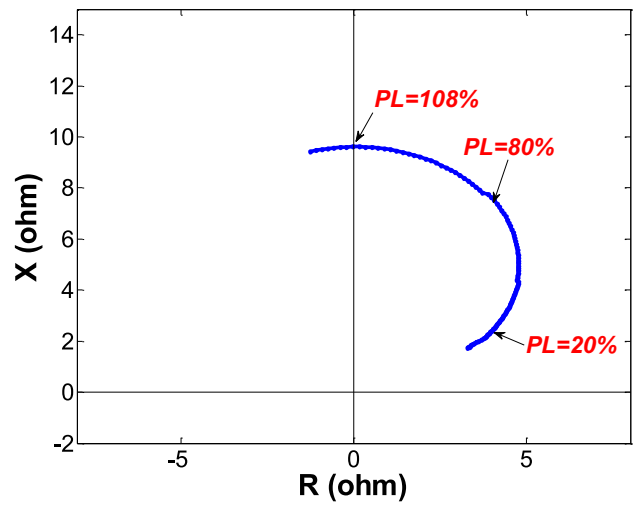

(a)

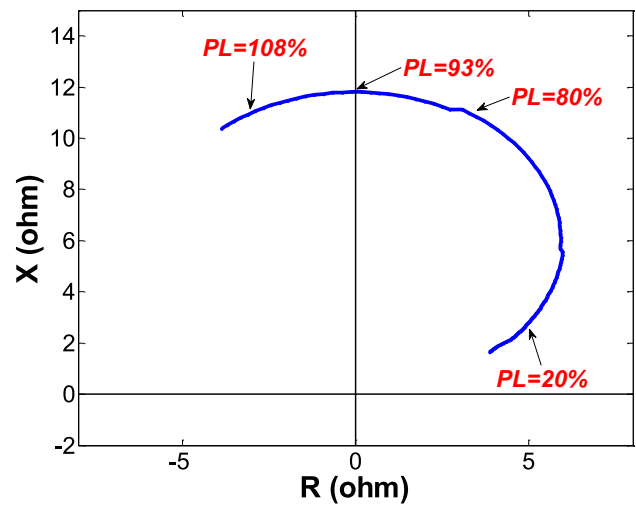

(b)

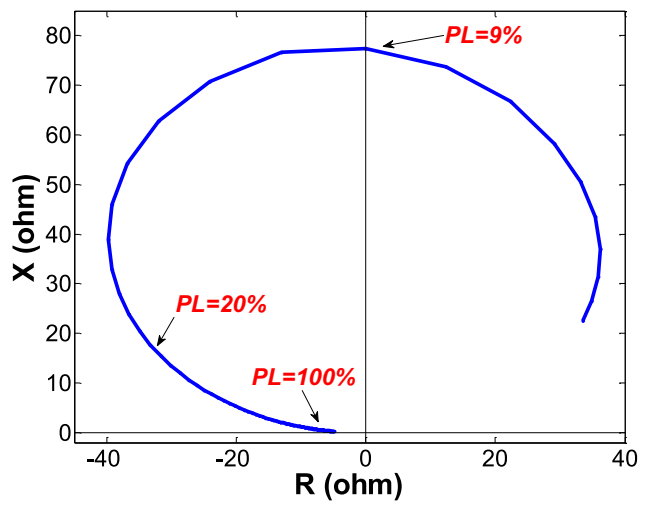

(c)

Fig. 7. Measured impedance at buses 632, 671, and 680 for PV installed at bus 680 and PL varies from zero to $115 \%$. (a) Measured impedance at bus 632-phase A. (b) Measured impedance at bus 671-phase A. (c) Measured impedance at bus 680-phase A.

\section{B. Impedance Variation Due to Normal Load Deviation}

Continuous load variation is the intrinsic characteristic of distribution system. In the last section, it was shown that the apparent impedance seen by measuring devices has a distinctive changes due to different PV PLs. Fig. 8 illustrates the typical normalized load patterns applied to the test feeder.

Fig. 9 shows the measured impedance trajectories for daily load variation. It is found that the small variation of load shows its impact on the measured impedance. For example, the measured impedance for phase $A$ changes from $6.785+\mathrm{j} 2.463 \Omega$ at the lightest load condition $(58 \%$ of nominal load) to $3.484+\mathrm{j} 1.782 \Omega$ for the maximum 


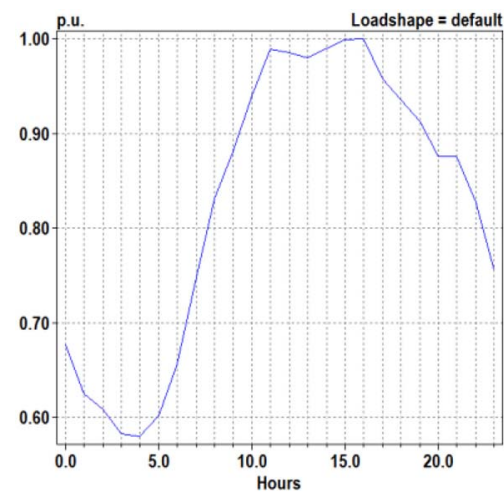

Fig. 8. Normalized load patterns of residential loads.



Fig. 9. Three-phases measured impedance at bus 632 for normal load variation condition.

daily load. The difference between the measured impedances are due to the unbalanced loading of distribution system.

\section{Analyzing the Impact of Unbalanced Distribution System on the Measured Impedance}

Unbalance operation is an intrinsic characteristic of distribution system. It is anticipated that when the voltage and current of the three-phases are unbalanced, the resultant measured impedance for each phase is not the same as in the other phases.

For a PV device installed at bus 680 Fig. 10 shows the loci of measured impedance for each phase at bus 632. It is worth mentioning that reversed power starts at different PL for each phase. While the impedance location for the phase $A$ and $C$ enters the second quarter of $R-X$ plane (for $\mathrm{PL}=108 \%$ and $111 \%$, respectively) showing small reversed active power, at the same PL, phase B shows a higher reversed active power. This phenomenon is due to the unbalanced operation of IEEE 13 node test feeder. It is concluded that for distribution system, any proposed technique shall be capable to monitor each phase separately.

Due to the three-phase balanced loads installed at bus 680 , it is anticipated that the measured impedance in each phase shall show the same trend. Fig. 11 shows the impedance trends



Fig. 10. Three-phases measured impedance at bus 632 .

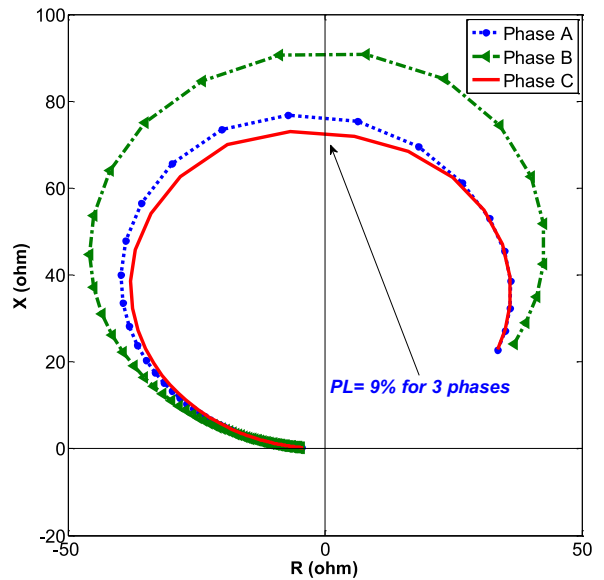

Fig. 11. Unbalanced voltage effects on three-phases measured impedance at bus 680 .



Fig. 12. Measured impedance at buses 632, 671, and 680 for PV installed at bus 671 .

at bus 680. Although the reversed power occurs at the same $\mathrm{PL}=9 \%$, the loci of measured impedance are not the same in each phase. Because the feeder 671-680 is fed with unbalanced voltages at bus 671 , small differences can be seen on the three phases impedance loci at bus 680 .

Fig. 12 shows the phase-B impedance trends for the same condition except for the location of PV system which connected to the bus 671 . It can be clearly seen that while the impedance seen from buses 671 and 632 varies a lot with PL 


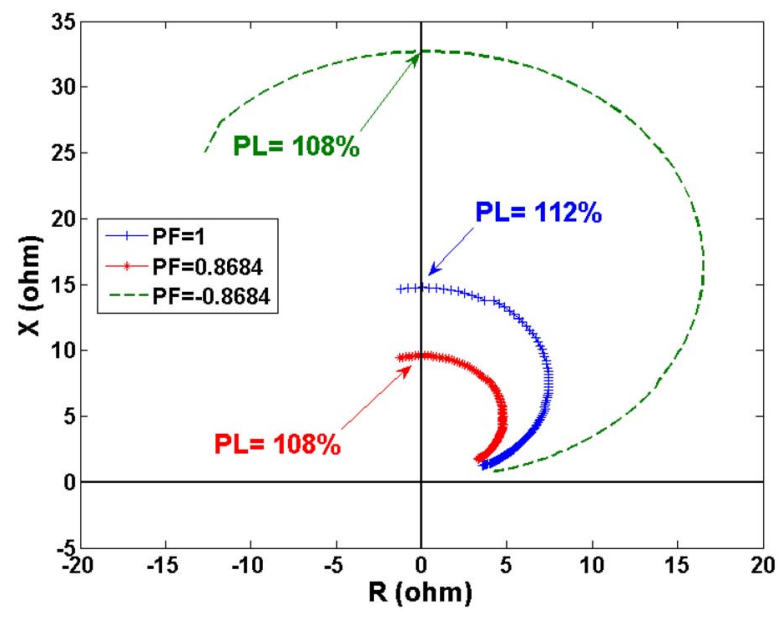

Fig. 13. Measured impedance at bus 632-phase A, for three different load pfs connected to bus 671 .

variation, the impedance seen from bus 680 contains a small variation due to bus 680 voltage changes.

Figs. 10-12 show that the measured impedance has clear reaction for downstream various PV penetrations. Meanwhile, its reaction to upstream PV variation is limited to feeder voltage deviation.

\section{Impact of Load pf Variation}

Distribution system loads profiles vary from line to line. The load pf varies in accordance with active and reactive power consumed by the load. Fig. 13 shows the effect of load pf variation on the measured impedance. For simulation the same condition of Fig. 7 (lumped PV connected to bus 680) is used, except that the pf of load connected to bus 671 (the biggest load in the test model) is changing form the lagging 0.8684 to unity $\mathrm{pf}$ and then to a 0.8684 leading one. As it was expected for each pf, the impedance trend varies. For unit pf, the reversed active power happens at bigger PL due to increased load active power. On the other hand, for $\mathrm{pf}=-0.8684$, although the reversed active power happened at the same condition of positive $\mathrm{pf}=0.8684$ but the impedance trend moves further against the origin. This happens because the negative pf means the VAr generation. Based on (20), any power generation along the line will decrease the line current, resulting the bigger impedance (any generation connected to line, acts as light load situation).

\section{E. Impact of Nonunit pf Operation of PV Inverter}

As it was stated earlier, some DG connection standards such as IEEE 1547 forbid the nonunit pf operation of distributed generation. Some publications [1], [2], [32] consider the advantages of using RES inverter capability for voltage support. To analyze the impact of nonunit pf operation of PVs, three situations are simulated with inverter capable to operate at $\mathrm{pf}=1,0.95$, and 0.9. For example at $\mathrm{pf}=0.9$ with the same size inverter, the maximum active power produced by PV units is limited to $90 \%$ of nominal power but at the same time the system has the capability to produce reactive power around $43 \%$ of nominal power to support voltage profile. For this simulation, the PV inverter size does not change.

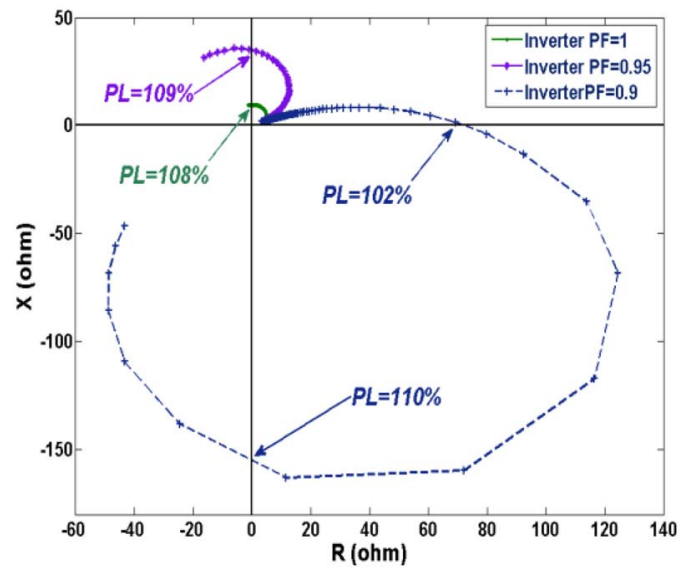

Fig. 14. Measured impedance at bus 632-phase A for three different PV inverter output pfs.

For PV installed at bus 680 and PL variation from zero to $115 \%$, Fig. 14 shows the impact of PV inverter pf variation on the apparent measured impedance trend. For simplicity, the results of phase A of bus 632 are only shown. It is anticipated that by nonunit operation of PV system and with reactive power generation, some feeders experience not only reverse active power but also reverse reactive power too. As shown in Fig. 14, by decreasing the pf from 1 to 0.95 (with the same inverter size) the reversed active power happened at bigger PL. For $\mathrm{pf}=0.90$, due to the reactive power generation of $\mathrm{PV}$ inverter the impedance trend moves from region 1 to 4 at $\mathrm{PL}=102 \%$ (shows the reversed reactive power with forward active power) and then finally enters to third region at the $\mathrm{PL}=110 \%$.

\section{F. Investigating the Measured Impedance Trends During Fault}

RES integration to distribution feeder will change the feeder fault current. Depend on the size and location of RES, the contribution of this generation to fault current varies [33]. At this condition, nondirectional over-current protections will operates for reverse faults, upstream of the protected zone. Therefore some utilities [33], [34], at their interconnection standard of DG to distribution system, recommend to install a distance relay. For example, Hydro-Quebec does not accept over current relay as the main protection and recommend to install a distance relay for conditions such as: outage of one of DG installed in the feeder, intermittent DG generation characteristic, and etc.

In this section the impact of fault on the feeder is investigated on the measured impedance trend. In normal operation of feeder, the measured apparent impedance is the combination of the feeder impedance and the equivalent impedance of total connected loads. Considering the compensation impact of capacitor bank on feeder pf, the load impedance normally is very close to real axis. During the fault condition, the measured impedance has a measurable decrease [for example at phase A, from $(3.966+\mathrm{j} 7.12)$ to $(0.08+\mathrm{j} 0.2) \Omega]$ and it moves toward the origin. The final location of the measured impedance is determined by the type of fault and the 


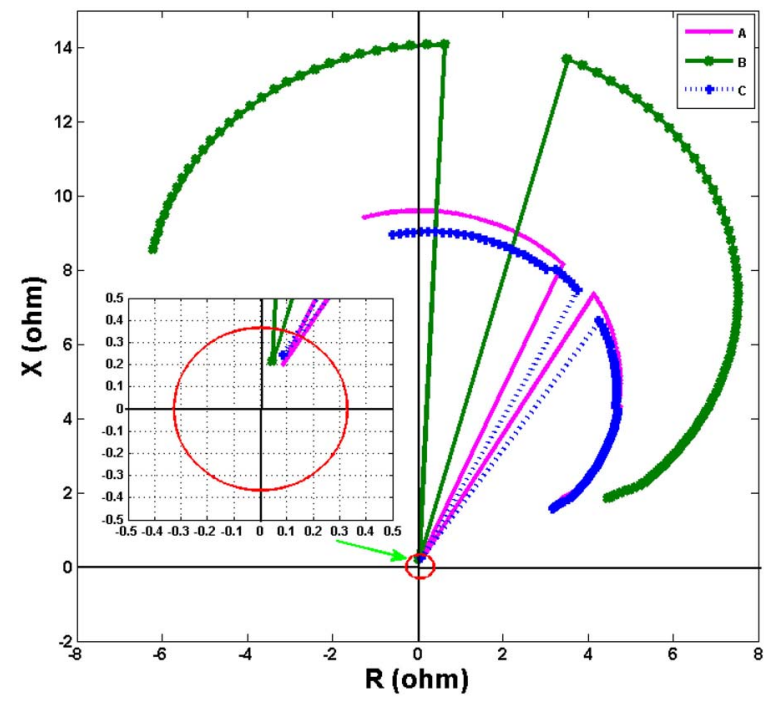

Fig. 15. Measured impedance at bus 632 for three-phase to ground fault at bus 671 . The small red circle is a nondirectional impedance relay.

fault impedance. The value of the apparent impedance during the fault is very close to the actual impedance of feeder between the measuring point and fault point plus the fault impedance.

Fig. 15 shows the trend of measured impedance at bus 632 for a three-phases to ground short circuit occurred at bus 671 . A nondirectional impedance relay is defined with the $80 \%$ of lines 632-671 impedance as setting. This protection is shown by the red circle in Fig. 15. A thorough investigation shows that the measured fault impedance value is settled down in the defined protection zone.

Furthermore to substantial decreases of impedance during the fault, by increasing the PL of RES, the resultant impedance will be increased. Considering (9), by increasing the RES penetration, the current flow through the line decreases and the measured impedance will be increased. According to the distance relay literature and the result of this section, it is shown that the fault zone is completely different than normal operation of measured impedance.

\section{G. Analyzing the Capability of Proposed Method for Fast Transients}

Normally distribution system loads are unbalanced, time varying [28]. By integration of RES like wind and solar, the distribution system faces intermittent and fast transients like in distributed generation.

For PV systems, the solar irradiation energy varies slowly over time from sun rise to sunset with a preknown patterns correlated with the longitude and latitude of installation site. The faster transient involved with solar generation is related to cloud movements. The PV system generation fluctuation is function of many factors. The centralized or distributed PV system, the total installed capacity, local weather pattern and the PV panel type are the main important factors which determine the transient characteristic of PV system output [35].

The cloud movement causes a fast transient on PV generation, and is one of the biggest challenges for increasing

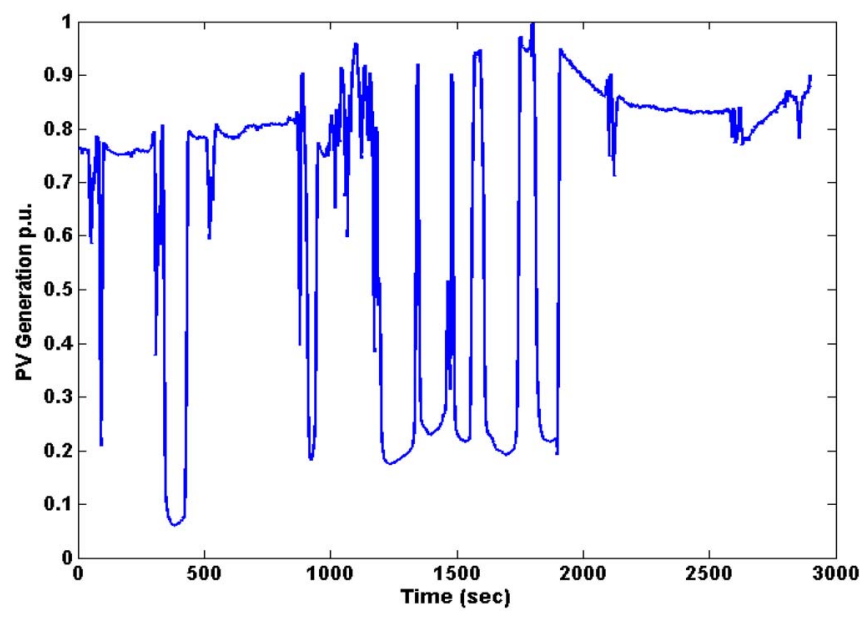

Fig. 16. Cloud transients impact on PV output [35].

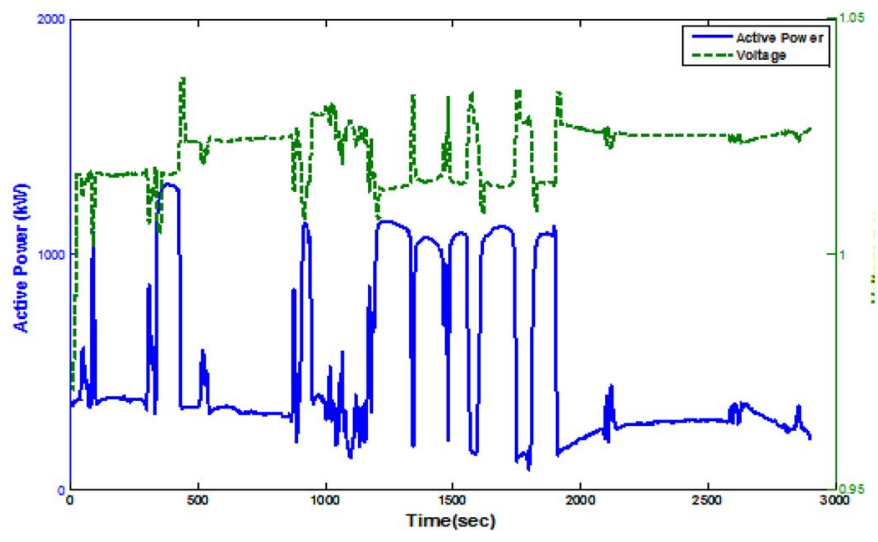

Fig. 17. Voltage and active power variation at bus 632 for PV installed at bus 680 while cloud passing transients.

the PV installation. Basically after a cloud movement over the installation site, the PV generation decreases dramatically. Afterward a solar ramp will increase the output of PV system. For distributed rooftop PV, these types of transients have less challenge for distribution system operation due to the little possibilities of simultaneous ramp up and down of all PV units. The PV plant size, its layout, wind speed and cloud movement direction are dominant factors affecting the generation and consequently the feeder voltage profile [35]. In other hand, for PV farm where all the PV panels are installed in a small area, the impact of cloud transients is substantial on operation and control of distribution system [36].

In this part of this paper, the impedance method capability will be analyzed by fast transient of cloud movement. Fig. 16 shows the 2900 s simulation of cloud movement on PV system generation [35]. The time interval between each sample is one second. As it was stated earlier, among two options of modeling high penetration of small-scale distributed rooftop PV or large centralized PV, the second one was chosen for the simulation of impedance based monitoring system. Therefore, due to smaller installation area of centralized PV system, the cloud movement transient impact will be severe.

For the PV system installed at bus 680, Fig. 17 shows the impact of cloud transients on the active power and voltage of 


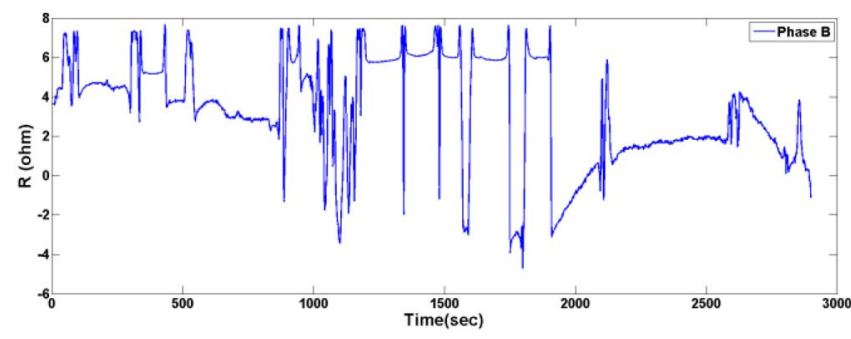

Fig. 18. Cloud transients impact on measured $R$ at bus 632 .

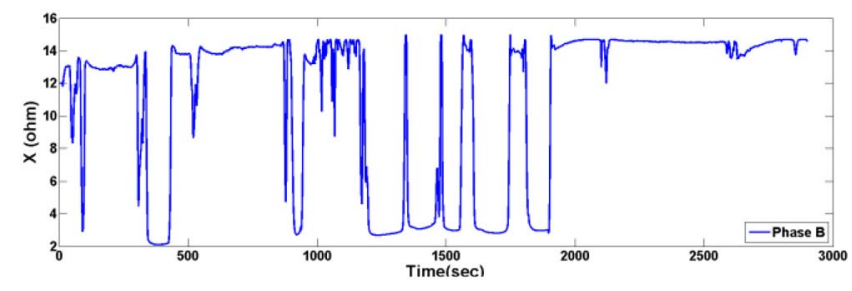

Fig. 19. Cloud transients impact on measured $X$ at bus 632 .

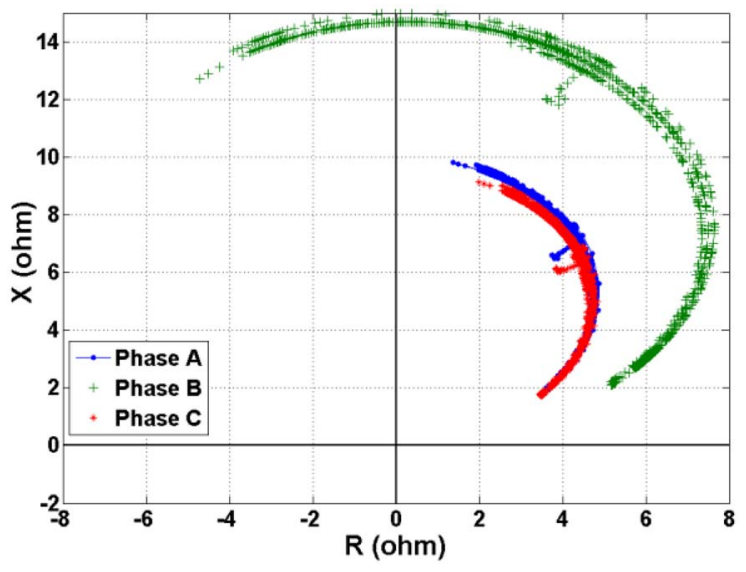

Fig. 20. Cloud transients impact on measured impedance at bus 632 .

bus 632 (connected to the substation bus). In some cases the PV system output ramp down from 1 to 0.4 p.u. in less than $15 \mathrm{~s}$ (for example check between 1800 to $1820 \mathrm{~s}$ at Fig. 16).

In comparison with Fig. 4, these fast transients cause high fluctuation in power flow and consequently high operation of tap changers. Due to the time constant of tap changer operation, the consumer electric devices experience some short term low voltage (when the cloud blocks the sun) and over voltage (when the cloud passes away). Figs. 18 and 19 show the impact of cloud movement transients on measured $R$ and $X$ at bus 632. As it can be seen the impedance method can react to fast transients in distribution system operation due to its simplicity of calculations.

Fig. 20 shows the measured impedance at bus 632 on the three-phases for the cloud transients. Although the high spatial diversity of $R$ and $X$ associated cloud movement, the mapped $R$ and $X$ on the impedance plane shows a special and detectable trend for each phase. In the next section, it will be shown that by defining different operation area on the $R-X$ plane this monitoring technique can be used as a practical tool for better operation of distribution system.

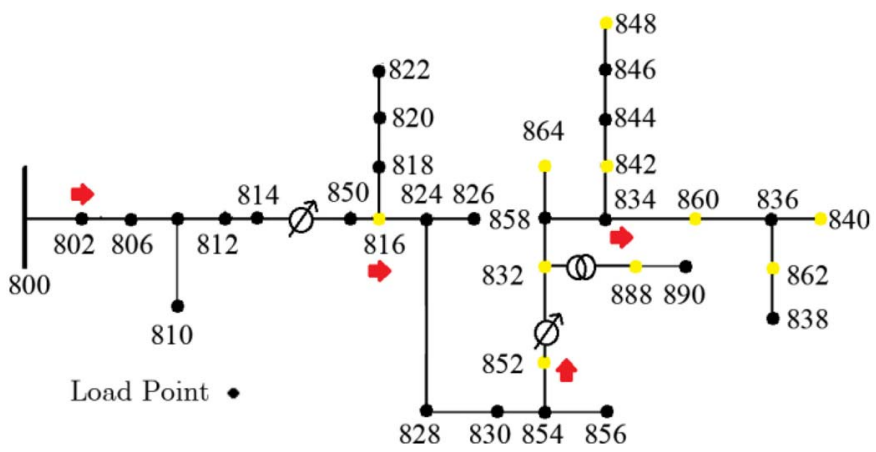

Fig. 21. IEEE 34 node test feeder. Nine $200 \mathrm{~kW}$ PV unit installed at yellow buses. The location and direction of four impedance measuring units are shown by red arrow [38].

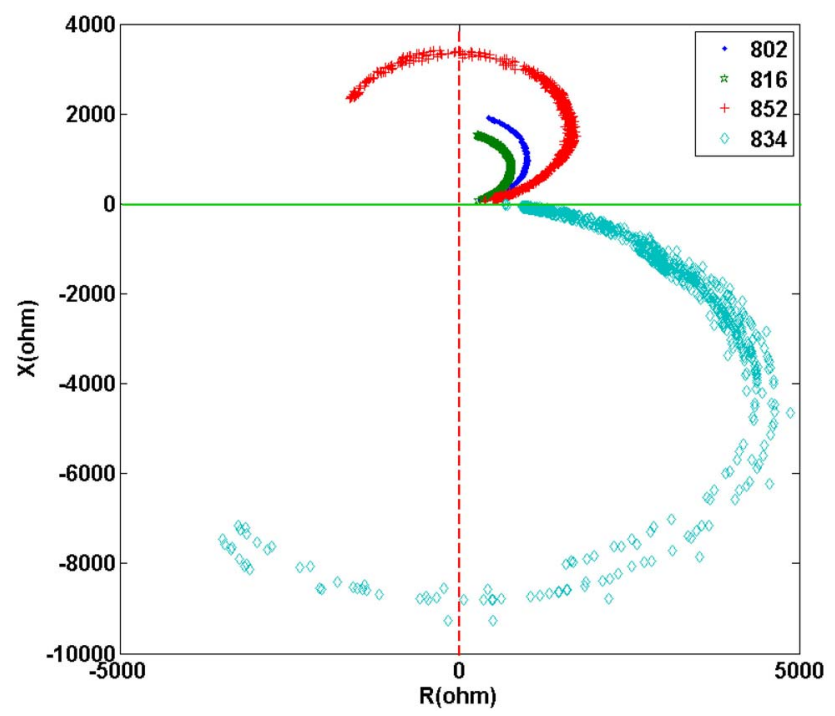

Fig. 22. Cloud transients impact on measured impedance (for phase A) at four buses. The red line shows the reverse active power starting point. The light green line shows the reverse reactive power starting point.

\section{H. Practical Application of Impedance Method}

To show a practical application of the impedance based monitoring system, the IEEE 34 Node Test Feeder is chosen. This test feeder is an actual feeder located in Arizona [28]-[37]. This unbalanced feeder has both spot and distributed load. For PV integration nine distributed $200 \mathrm{~kW}$ PV units are connected to feeder in different locations as shown in Fig. 21. Four impedance measuring units are connected to buses $802,816,852$, and 834 . The location and direction of measuring units are shown in Fig. 21 by the red arrow.

Considering the worst case operation of PV units, the cloud movement pattern shown in Fig. 16 is used as the PV unit sun irradiation input. Fig. 22 shows the apparent impedance trend measured at those four locations in response to the cloud movement. For simplicity, only the phase-measured impedances are shown. While the impedance trend shows the reversed active power for bus 852, the bus 834 shows the reversed active and reactive power. This phenomena happens due to the two capacitors installed at the buses 848 (450 kvar) and 844 (300 kvar). 

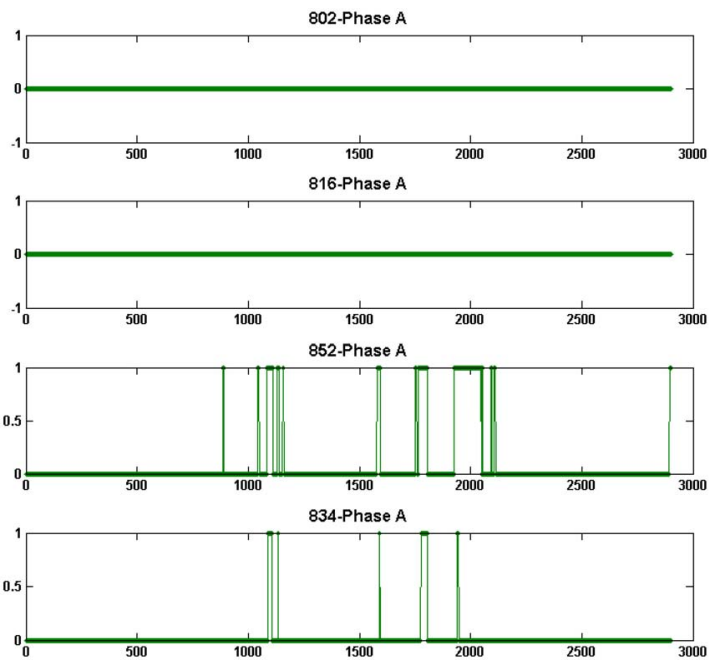

Fig. 23. Alarm issued for reversed active power at different buses (phase A).

However, considering the speed and the type of events, some rules and alarm settings can be defined in the impedancebased method to send alarms or actions to the distribution system operator or to controlling devices installed at distribution system. For example, in some utilities it is forbidden for distribution system to feed the transmission system. To implement this limitation, a flag was defined in the monitoring system to generate an alarm. For normal operation the flag is zero and for reversed power detection at the measuring point the flag changes from zero to one and an alarm is issued.

Fig. 23 shows the defined alarm output for reverse power detection at four measuring points. As it can be seen from Figs. 22 and 23 at buses 852 and 834 the phase A undergoes some reversed active power due to transient of cloud passing. Therefore, the alarm is issued repeatedly, whenever reversed active power happens. On the other hand, for buses 802 and 816, no alarms are issued.

As it was stated earlier, due to two capacitor installed at buses 848 and 844 for pf correction, power flow analysis shows the permanent reversed reactive power at bus 834 . Therefore, a flag is defined for reversed reactive power detection. This limitation is shown in Fig. 22 by light green line.

Fig. 24 shows alarms issued for both reversed active and reactive power, the result is shown for phase C. Due to unbalanced characteristic of IEEE 34 node, unlike the phase A as shown in Fig. 22, the phase $\mathrm{C}$ undergoes reverse power (both active and reactive) not only at buses 834 and 852 but also for buses 802 and 816 . For instance, bus 802 -phase $C$ shows reversed active power for short period of times, on the other hand, endures reverse reactive power for most of the times.

This paper has outlined a monitoring application of apparent impedance measurement. It was shown that the apparent impedance has considerable capability to use as a monitoring technique for reverse power flow detection at any condition. Because, based on (22) and (23), any point (r, x) on the $R-X$ coordinates plane is in one-to-one correspondence with a point (p, q) in the $P-Q$ coordinates plane. Meanwhile, the application of the method after a substantial changes in the
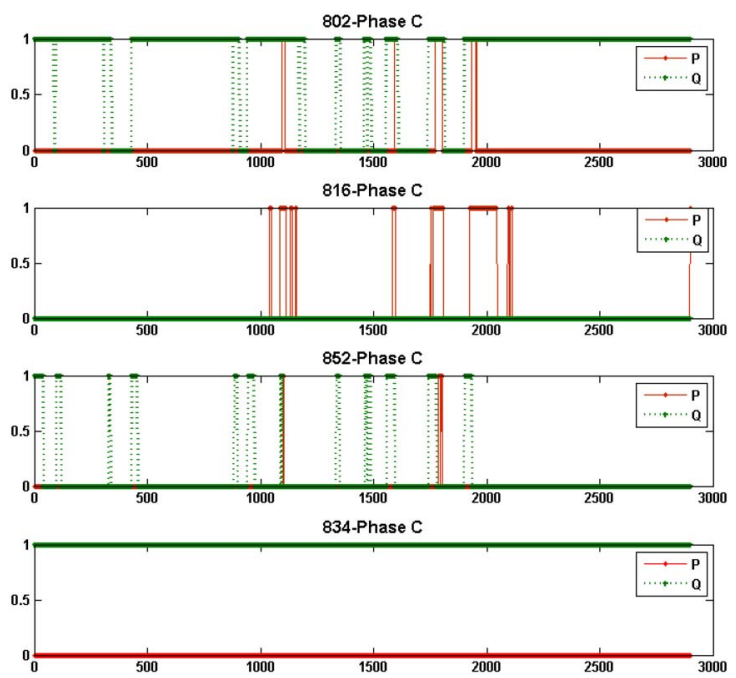

Fig. 24. Alarm issued for reversed active and reactive power at different buses (phase C).

grid like islanding need to be investigated. After islanding, the power flow direction in the micro-grid may be changed. The application of the proposed method for islanded microgrid is the same as protection device application. Therefore, the optimal location and setting for the measuring unit will be affected by islanding. Work is continuing in order to put the method to practical use. The defined alarm and action output of this monitoring technique can be combined with current voltage controller of the feeder for better voltage regulation in presence of RES.

\section{CONCLUSION}

In this paper, an impedance-based monitoring technique for evaluation of current situations of distribution system has been presented.

The main contribution of this paper is based on measured impedance that has high capability for detecting different states of distribution system in presence of various PV PLs.

The results indicate that any proposed monitoring technique shall have the capability of monitoring for balanced and unbalanced system. The dynamic capability of the proposed method has been tested by monitoring the fast transient phenomena such as cloud movement on centralized PV units under unbalanced system conditions of the IEEE 34-bus three-phase distribution network.

A practical application of the proposed method is simulated to show the capabilities of measured impedance to monitor and control of distribution system in presence of various PLs of PV. Authors are working on using this method for voltage control improvement of distribution system with high PV integration.

\section{REFERENCES}

[1] P. Jahangiri and D. C. Aliprantis, "Distributed Volt/VAr control by PV inverters," IEEE Trans. Power Syst., vol. 28, no. 3, pp. 3429-3439, Aug. 2013.

[2] W. Yang, Z. Peng, L. Wenyuan, X. Weidong, and A. Abdollahi, "Online overvoltage prevention control of photovoltaic generators in microgrids," IEEE Trans. Smart Grid, vol. 3, no. 4, pp. 2071-2078, Dec. 2012. 
[3] M. Asari and H. Kobayashi, "Method of controlling reverse power flow of PV system with heat pump water heater," in Proc. 3rd IEEE PES Int. Conf. Exhibit. Innov. Smart Grid Technol. (ISGT Europe), Berlin, Germany, 2012, pp. 1-6.

[4] M. E. Baran, H. Hooshyar, S. Zhan, and A. Huang, "Accommodating high PV penetration on distribution feeders," IEEE Trans. Smart Grid, vol. 3, no. 2, pp. 1039-1046, Jun. 2012.

[5] N. Daratha, B. Das, and J. Sharma, "Coordination between OLTC and SVC for voltage regulation in unbalanced distribution system distributed generation," IEEE Trans. Power Syst., vol. 29, no. 1, pp. 289-299, Jan. 2014.

[6] T. Aziz, M. Hossain, T. Saha, and N. Mithulananthan, "VAR planning with tuning of STATCOM in a DG integrated industrial system," IEEE Trans. Power Del., vol. 28, no. 2, pp. 875-885, Apr. 2013.

[7] C. S. Chen, C. H. Lin, W. L. Hsieh, C. T. Hsu, and T. T. Ku, "Enhancement of PV penetration with DSTATCOM in Taipower distribution system," IEEE Trans. Power Syst., vol. 28, no. 2, pp. 1560-1567, May 2013

[8] K. Byung-Kwan, K. Seung-Tak, B. Sun-Ho, and P. Jung-Wook, "Effect of a SMES in power distribution network with PV system and PBEVs," IEEE Trans. Appl. Supercond., vol. 23, no. 3, Jun. 2013, Art. ID 5700104

[9] P. Goli and W. Shireen, "PV integrated smart charging of PHEVs based on DC link voltage sensing," IEEE Trans. Smart Grid, vol. 5, no. 3, pp. 1421-1428, May 2014.

[10] F. Marra, Y. Guangya, C. Traeholt, J. Ostergaard, and E. Larsen, "A decentralized storage strategy for residential feeders with photovoltaics," IEEE Trans. Smart Grid, vol. 5, no. 2, pp. 974-981, Mar. 2014.

[11] J. von Appen, T. Stetz, M. Braun, and A. Schmiegel, "Local voltage control strategies for PV storage systems in distribution grids," IEEE Trans. Smart Grid, vol. 5, no. 2, pp. 1002-1009, Mar. 2014.

[12] H. Taheri, O. Akhrif, and A. F. Okou, "Contribution of PV generators with energy storage to grid frequency and voltage regulation via nonlinear control techniques," in Proc. 39th Annu. Conf. IEEE Ind. Electron. Soc. (IECON), Vienna, Austria, 2013, pp. 42-47.

[13] K. Ogimoto, I. Kaizuka, Y. Ueda, and T. Oozeki, "A good fit: Japan's solar power program and prospects for the new power system," IEEE Power Energy Mag., vol. 11, no. 2, pp. 65-74, Mar./Apr. 2013.

[14] J. Appen, M. Braun, T. Stetz, K. Diwold, and D. Geibel, "Time in the sun: The challenge of high PV penetration in the German electric grid," IEEE Power Energy Mag., vol. 11, no. 2, pp. 55-64, Mar./Apr. 2013.

[15] R. Tonkoski, L. A. C. Lopes, and T. H. M. El-Fouly, "Coordinated active power curtailment of grid connected PV inverters for overvoltage prevention," IEEE Trans. Sustain. Energy, vol. 2, no. 2, pp. 139-147, Apr. 2011.

[16] M. P. Tcheou et al., "The compression of electric signal waveforms for smart grids: State of the art and future trends," IEEE Trans. Smart Grid, vol. 5, no. 1, pp. 291-302, Jan. 2014.

[17] I. F. Visconti, D. A. Lima, J. M. C. de Sousa Costa, and N. Rabello de B. C. Sobrinho, "Measurement-based load modeling using transfer functions for dynamic simulations," IEEE Trans. Power Syst., vol. 29, no. 1, pp. 111-120, Jan. 2014.

[18] F. Qiang et al., "Microgrid generation capacity design with renewables and energy storage addressing power quality and surety," IEEE Trans. Smart Grid, vol. 3, no. 4, pp. 2019-2027, Dec. 2012.

[19] H. Shateri and S. Jamali, "Measured impedance at source node of a distribution feeder for inter phase faults," in Proc. IEEE PES Transmiss. Distrib. Conf. Expo., Vancouver, BC, Canada, 2010, pp. 1-6.

[20] K. Vu, M. M. Begovic, D. Novosel, and M. M. Saha, "Use of local measurements to estimate voltage-stability margin," IEEE Trans. Power Syst., vol. 14, no. 3, pp. 1029-1035, Aug. 1999.

[21] M. Cespedes and S. Jian, "Adaptive control of grid-connected inverters based on online grid impedance measurements," IEEE Trans. Sustain. Energy, vol. 5, no. 2, pp. 516-523, Apr. 2014.

[22] I. Chilvers, N. Jenkins, and P. Crossley, "Distance relaying of $11 \mathrm{kV}$ circuits to increase the installed capacity of distributed generation," IEEE Proc. Gener. Transmiss. Distrib., vol. 152, no. 1, pp. 40-46, Jan. 2005.

[23] D. Uthitsunthorn and T. Kulworawanichpong, "Distance protection of a renewable energy plant in electric power distribution systems," in Proc. Int. Conf. Power System Technol. (POWERCON), Hangzhou, China, 2010, pp. 1-6.

[24] J. Roberts, A. Guzman, and E. O. Schweitzer, III, " $\mathrm{Z}=\mathrm{V} / \mathrm{I}$ does not make a distance relay," in Proc. Annu. Western Protect. Relay Conf. (WPRC), Spokane, WA, USA, 1993, pp. 19-21.
[25] C. R. Mason, The Art and Science of Protective Relaying. Hoboken, NJ, USA: Wiley, 1956.

[26] Y. Hase, Handbook of Power System Engineering. Hoboken, NJ, USA: Wiley, 2007.

[27] H. Shateri and S. Jamali, "Measured impedance by distance relay elements applied on a distribution feeder in a single phase to ground fault," in Proc. IEEE/PES Power Syst. Conf. Expo. (PSCE), Seattle, WA, USA, 2009, pp. 1-7.

[28] W. H. Kersting, Distribution System Modeling and Analysis. Boca Raton, FL, USA: CRC Press, 2012.

[29] R. C. Dugan, Reference Guide: The Open Distribution System Simulator (OpenDSS), Elect. Power Res. Inst. Inc., Palo Alto, CA, USA, 2012.

[30] Using Matlab Version 5 Guide, The Mathworks, Inc., Natick, MA, USA, vol. 5, 1998.

[31] A. Hoke, R. Butler, J. Hambrick, and B. Kroposki, "Steady-state analysis of maximum photovoltaic penetration levels on typical distribution feeders," IEEE Trans. Sustain. Energy, vol. 4, no. 2, pp. 350-357, Apr. 2013.

[32] H. Vahedi, K. Al-Haddad, Y. Ounejjar, and K. Addoweesh, "Crossover switches cell (CSC): A new multilevel inverter topology with maximum voltage levels and minimum DC sources," in Proc. 39th Annu. Conf. IEEE Ind. Electron. Soc. (IECON), Vienna, Austria, 2013, pp. 54-59.

[33] Requirements for the Interconnection of Distributed Generation to the Hydro-Québec Medium-Voltage Distribution System (Between $750 \mathrm{~V}$ to 44000 V), Hydro-Québec Standard E.12-01, 2004.

[34] Distributed Generation Technical Interconnection RequirementsInterconnections at Voltages $50 \mathrm{kv}$ and Below, Rev. 3, Hydro One Networks Inc. Standard DT-10-015, 2013.

[35] R. C. Dugan and T. E. McDermott, "An open source platform for collaborating on smart grid research," in Proc. IEEE Power Energy Soc. Gen. Meeting, San Diego, CA, USA, 2011, pp. 1-7.

[36] T. Godfrey et al., "Modeling smart grid applications with co-simulation," in Proc. 1st IEEE Int. Conf. Smart Grid Commun. (SmartGridComm), Gaithersburg, MD, USA, 2010, pp. 291-296.

[37] K. Christakou, J. LeBoudec, M. Paolone, and D. C. Tomozei, "Efficient computation of sensitivity coefficients of node voltages and line currents in unbalanced radial electrical distribution networks," IEEE Trans. Smart Grid, vol. 4, no. 2, pp. 741-750, Jun. 2013.

[38] S. Shafiee, M. Fotuhi-Firuzabad, and M. Rastegar, "Investigating the impacts of plug-in hybrid electric vehicles on power distribution systems," IEEE Trans. Smart Grid, vol. 4, no. 3, pp. 1351-1360, Sep. 2013.

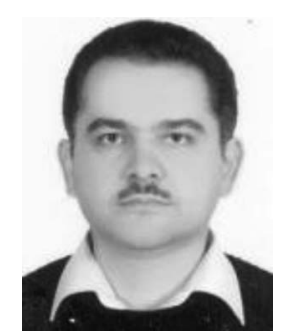

Hashem Mortazavi received the B.Sc. and M.Sc. (Hons.) degrees in electrical engineering from the Ferdowsi University of Mashhad, Mashhad, Iran, in 1998 and 2001, respectively. $\mathrm{He}$ is currently pursuing the Ph.D. degree in electrical engineering from Quebec University (École de Technologie Supérieure), Montreal, QC, Canada.

His current research interests include smart grid, renewable energy integration, and generation protection coordination.

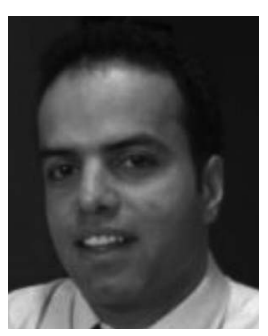

Hasan Mehrjerdi (M'14) received the B.Sc. and M.Sc. degrees in electrical engineering from the Ferdowsi University of Mashhad, Mashhad, Iran, and Tarbiat Modares University, Tehran, Iran, in 1998 and 2002, respectively, and the Ph.D. degree in electrical engineering from Quebec University (École de Technologie Supérieure), Montreal, QC, Canada, in 2010.

From 2011 to 2013, he was with the Department of Power Systems and Mathematics, Research Institute of Hydro-Quebec, Varennes, QC, Canada. In 2014, he was at Abengoa Research, Seville, Spain, as a Senior Power System Researcher. In 2015, he joined Qatar University, Doha, Qatar, as an Assistant Professor. His current research interests include power system and control studies, integration of renewable energy resources, and smart grid. 


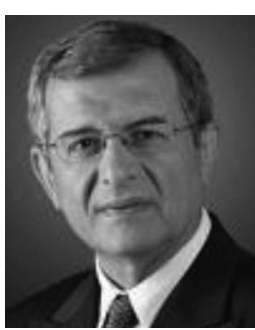

Maarouf Saad (SM'08) received the Bachelor's and Master's degrees from École Polytechnique of Montreal, Montreal, QC, Canada, in 1982 and 1984, respectively, and the Ph.D. degree from McGill University, Montreal, in 1988, all in electrical engineering.

He joined École de Technologie Supérieure, Montreal, in 1987, where he teaches control theory. His current research interests include nonlinear control and optimization applied to power systems, flight control, and robotics.



Serge Lefebvre received the Bachelor's and Master's degrees in electrical engineering from École Polytechnique de Montreal, Montreal, QC, Canada, and the Ph.D. degree in electrical engineering from Purdue University, West Lafayette, IN, USA.

He was involved in modeling and analysis of transmission and distribution systems at the Research Institute of Hydro-Quebec, Varennes, QC. His current research interests include energy and distribution management applications and evolution of the network toward a smart grid.

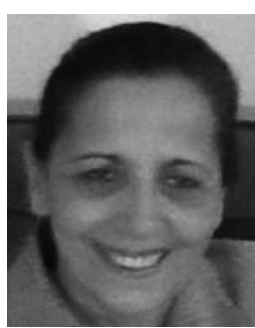

Dalal Asber received the B.Sc. degree in electrical engineering from the University of Damascus, Damascus, Syria, in 1979, and the M.Sc. and Ph.D. degrees in automatic control from Institut National Polytechnique, Nancy, France, in 1988 and 1991, respectively.

She was a Post-Doctoral Researcher at École de Technologie Supérieure, Montreal, QC, Canada. In 1993, she joined the Hydro-Quebec Research Institute, Varennes, QC, where she was involved in power system modeling, simulation, and control.

Laurent Lenoir (M'06) received the B.Sc. degree in electrical engineering from École Supérieure d'Ingénieurs en Électrotechnique et Électronique d'Amiens, Amiens, France; the M.Sc.A. degree from École Polytechnique de Montréal, Montreal, QC, Canada; and the Ph.D. degree in electrical engineering from École de Technologie Supérieure, Montreal, in 2001, 2004, and 2009, respectively.

He was at Hydro-Quebec Research Institute, Varennes, QC, where he was involved in power system operation in distribution and transmission networks, and evolution of the networks toward a smart grid. 